\title{
DEPENDENCE OF MAGNETIC HYSTERESIS UPON WAVE FORM.
}

\author{
By Morton G. Lloyd.
}

When the electromotive force applied to the magnetization of iron is simple harmonic, the wave of magnetic flux which it produces is also simple harmonic. When the curve representing the emf. is distorted from the sinusoidal shape, the magnetic flux will also be distorted, but in a different manner. In considering the energy losses, or transformations into heat, which take place in the iron in different cases, we may proceed from two different standpoints. If we consider the effective value of the electromotive force maintained constant while the form of wave is changed, we approximate the conditions of the practical use of transformers. Under these conditions the iron is magnetized to different maximum inductions with the different forms of wave, and large differences in the iron losses may result. This subject has been treated both theoretically and experimentally in a previous paper. ${ }^{1}$

If, on the other hand, the maximum magnetic induction is made the same with different wave forms, then the effective electromotive force is different and the eddy currents induced in the iron are different. Here, again, we shall have the energy loss in the iron different.

Our present problem is to separate this variable loss due to eddy currents from the loss due to magnetic hysteresis and determine whether the latter varies or is constant when the maximum value of the magnetic flux is kept constant while the form of the wave is varied. 
The formula given by Steinmetz assumes that the hysteresis loss is determined by the maximum magnetic induction. As modified by Rössler ${ }^{2}$ this formula reads

where

$$
W=\eta n B^{1.6}+\zeta n^{2} f^{2} B^{2}
$$

$B=$ maximum magnetic flux density.

$n=$ frequency.

$f=$ form factor of induced electromotive force.

$W=$ power expended per unit volume.

$\eta$ and $\zeta$ are constants of the iron.

The first term in the second member of the equation represents the hysteresis loss and the second term the loss due to eddy currents. The latter is assumed proportional to the square of the effective value of the induced emf. Now the maximum flux density is proportional to the average value of the induced emf., and since form factor is by definition the ratio of the effective to the average value, we have eddy current loss proportional to $(f B)^{2}$. The introduction of the form factor is the modification made by Rössler in order to apply the formula to waves which are not sinusoidal.

It is well known that this formula is not accurately true. Even with sine waves, the hysteresis is not strictly proportional to $B^{1.6}$, but within practical operating ranges it is approximately so. Similarly the eddy current loss may not be strictly proportional to $B^{2}$. We are concerned here, however, not with variations of $B$, but with variations of the loss when $B$ is kept constant.

To determine the constancy of the hysteresis loss it is necessary to separate the total iron loss into its two components, and determine the variation of the eddy current loss independently. With a constant form factor, this separation can be approximately accomplished by measurements at two frequencies and the same flux density. If the form factor is not the same at the two frequencies (and ordinarily it is not), it must be measured and used in the separation, as follows:

$$
\begin{aligned}
& W_{1}=\eta n_{1} B^{x}+\zeta n_{1}^{2} f_{1}^{2} B^{2} \\
& W_{2}=\eta n_{2} B^{x}+\zeta n_{2}^{2} f_{2}^{2} B^{2} \\
& \frac{W_{1}}{n_{1}}=\eta B^{x}+\zeta n_{1} f_{1}^{2} B^{2}
\end{aligned}
$$

${ }^{2}$ G. Rössler, Electrician, 36, p. I24; 1895. 
from which

$$
\begin{gathered}
\frac{W_{2}}{n_{2}}=\eta B^{n}+\zeta n_{2} f_{2}{ }^{2} B^{2} \\
\zeta B^{2}=\frac{W_{1}-\frac{W_{2}}{n_{2}}}{n_{1} f_{1}^{2}-n_{2} f_{2}{ }^{2}}
\end{gathered}
$$

Having determined $\zeta B^{2}$, the value of $\zeta n f^{2} B^{2}$ for each case, and the value of $\eta B^{x}$ are easily obtained. These represent the energy per cycle expended in eddy currents and in hysteresis respectively. Knowing these values for one wave form, the wave form may then be altered, the new form factor measured, and the new eddy current loss computed. The remainder of the measured loss is due to hysteresis.

If the original equation were an exact representation of the facts, this procedure would give an easy solution of the problem; but the equation is only an approximation. It assumes, first of all, that the hysteresis is independent of wave form in separating the two components of loss. This objection is avoided, however, if the separation is made with runs on the same form of wave, say a sine wave. Or if not exact sine waves, if the waves approach it closely, an approximately true separation would result by considering the form factors as indicated above. The test could then be made upon waves with widely varying form factors.

There are other assumptions in the equation, however, which may not correspond with fact. The question as to whether the hysteresis loss per cycle varies with the rapidity of performing the cycle is still an open question and one closely related to the problem in hand. The results obtained by different observers are so utterly diverse as to present no final answer to that question, but some of the results which have been published are so obviously spurious that they can not be considered as evidence. These researches will be discussed later. We may safely assume for present purposes that if there be a variation with frequency it is small, and within such limits as would here be used for the separation of the losses (say 30 and 60 cycles) the error introduced would also be very small. So much for the term representing hysteresis loss.

The term representing the loss by eddy currents is known to be only an approximation. If a series of measurements is taken at dif$59629-08-4$ 
[Vol. 5, No. 3 .

ferent frequencies, using a sine wave, it is found that the loss per cycle does not increase according to a linear law, as the equation indicates, but that at higher frequencies the observed values are smaller than would correspond to the observed values at the lower frequencies. This is illustrated in Fig. I, which shows the variation of total loss per cycle with the frequency in some sheets of

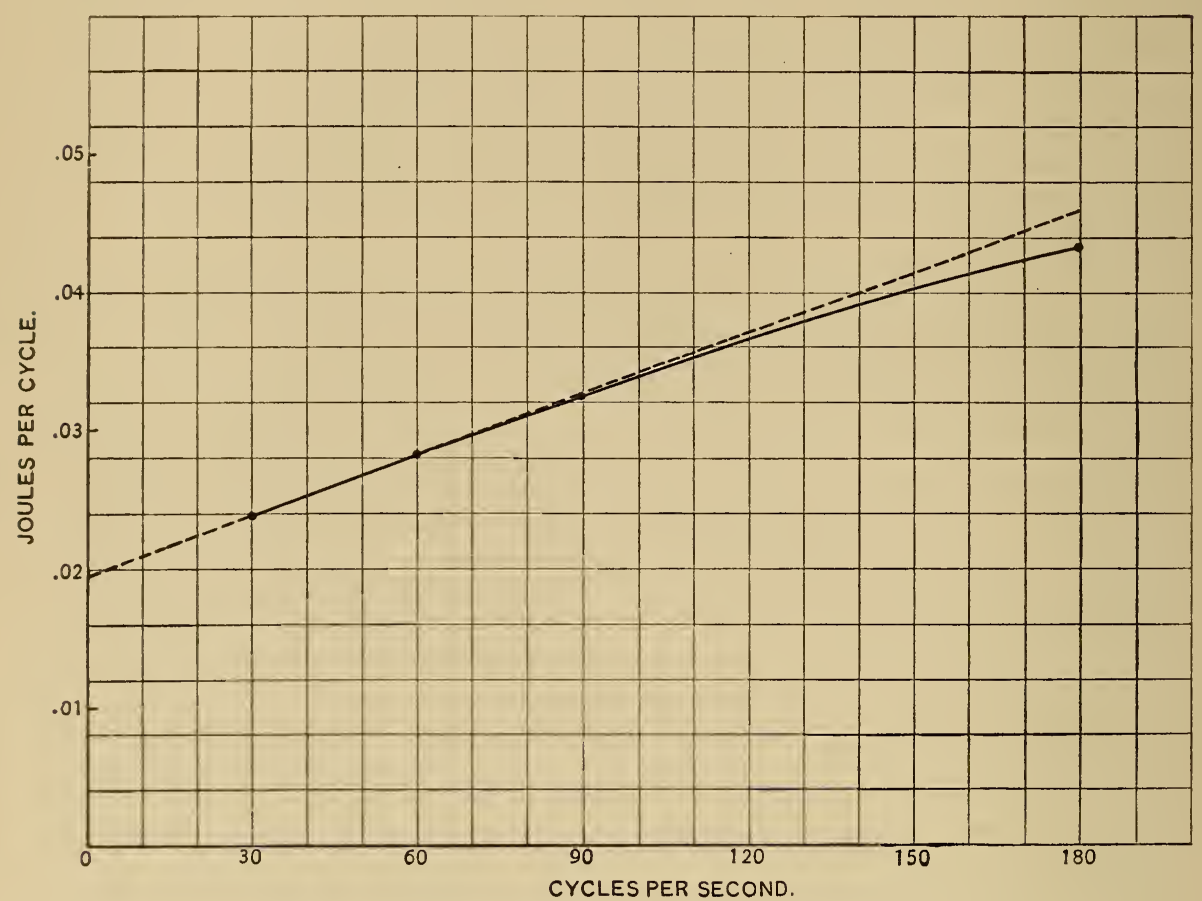

Fig. 1.-Transformer Sheet No. 27 Gage at 5000 gausses.

transformer iron which were tested with a sine wave. The dotted line is a straight line through the points for 30 and 60 cycles. The solid line connecting the observed values sags at the higher frequencies. This has been attributed by some writers to the inductance of the eddy current circuits, which makes itself appreciable at the higher frequencies, so that the proper expression for the energy is

$$
\frac{E^{2} R}{R^{2}+(2 \pi n L)^{2}} \text { instead of } \frac{E^{2}}{R}
$$


This expression decreases with increasing $n$. I have not, however, been able to fit such an expression to my experimental results, and I believe the cause is to be found in another action of the eddy currents. As the frequency increases the eddy currents are increased in magnitude and exert a greater magnetizing force. This is greater near the center of the cross-section, and has the well-known effect of concentrating the flux near the onter walls of the conductor. The distribution of flux consequently changes with the frequency, the amount of flux threading the shorter paths of eddy currents, as $a$, Fig. 2, being decreased, while the flux through the outer paths, as $c$, is unchanged. The result is that the mean length of circuit of the eddy currents is increased and the mean resistance increased, thus reducing the energy below its value for a uniform distribution. The hysteresis loss is also affected by the change in distribution.

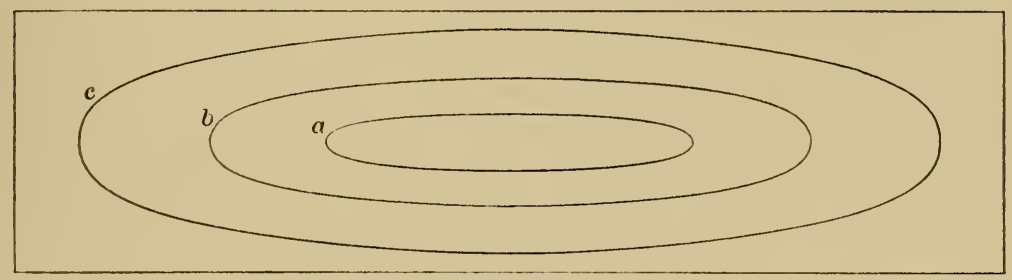

Fig. 2.

From this discussion we may conclude that an exact separation of the hysteresis and eddy current components of the energy loss can not be made upon the basis of the Steinmetz equation, but that an approximate separation can be made; and the accuracy of the separation will be greater the more nearly the following conditions are realized:

I. The two frequencies used should be low and as close together as the accuracy of observation will permit.

2. The form factor of secondary emf. should be the same at both frequencies.

3. The eddy current loss should be very small compared to the hysteresis loss.

The fulfillment of the first condition is limited by the fact that a given error of observation has a greater effect upon the results 
when the two frequencies are close together. In the present work 30 and 60 cycles are used exclusively.

The fulfillment of the second condition is limited by the fact that the wave is distorted by the ohmic drop of potential in the magnetizing circuit, and this effect is different at different frequencies. The magnetizing current changes but little with the frequency, while the induced emf. is proportional to the frequency. The distortion is therefore greater at lower frequencies. The best conditions are obtained when the resistance of the magnetizing circuit is low, when the iron is worked at maximum permeability, and when the cross-section of iron is large.

The third condition is best fulfilled by using wire of small diameter or sheets which are thin, by using steels of low electrical conductivity with large hysteresis, and by operating at low frequency. In the present work, transformer sheet was used for the first experiments, and later rings of steel wire. Finally, some wire of 0.002 inch diameter was obtained, in which the eddy currents were negligible.

\section{THE APPARATUS.}

The specimens experimented upon were mostly in ring form and consisted of sheet iron, both annealed and unannealed, and iron and steel wire of different diameters. A few measurements were made upon strips of transformer sheet built into a magnetic circuit after the manner of Epstein, but with less magnetic leakage. The specimen was wound with a magnetizing coil and with one or two secondary coils. The power was measured by a dynamometer wattmeter whose deflections were read by telescope and scale. The fixed coils of this instrument were traversed by the magnetizing current. The moving coil was connected to one of the secondary windings through a variable resistance or multiplier, which enabled a wide range of powers to be measured with equal accuracy-always better than O.I per cent. This wattmeter was calibrated with direct current. If $n_{1}$ is the number of turns in the magnetizing coil, and $n_{2}$ the number in the secondary coil, then $\frac{n_{1}}{n_{2}}$ times the wattmeter reading gives the power expended in the iron and in the secondary circuits. The effective voltage in the secondary circuits is measured by means of a dynamometer voltmeter. The square of this effective 
voltage divided by the resistance of any secondary circuit will give the power expended in that circuit, and this is applied as a correction to the measured watts. These corrections are never more than a few per cent.

The measurement of the maximum value of the magnetic flux, where the wave form is unknown, is not easy, and required the use of special apparatus, a description of which has already been published. ${ }^{3} \quad$ The value of the magnetic flux at any instant is proportional to the algebraic average of the induced electromotive force during the succeeding half cycle, providing the positive and nega-

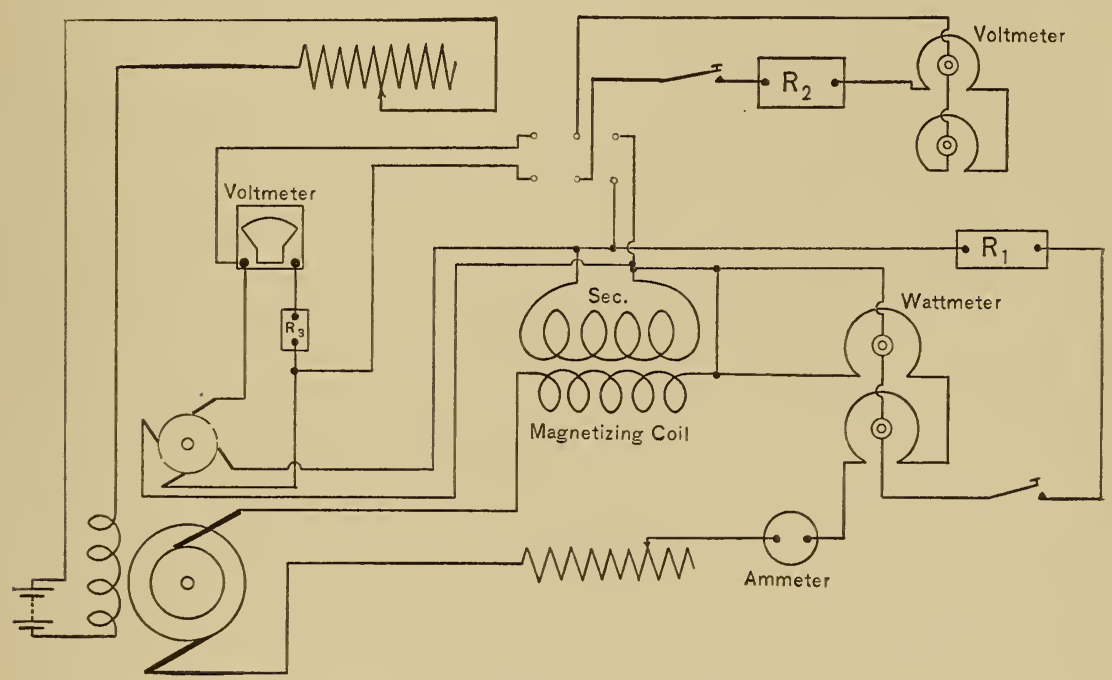

Fig. 3.-Diagram of Connections.

tive half waves are alike, as in the present case. The maximum value of the flux is given by the average value of the induced emf. during the half cycle beginning with the zero value. The average value of the emf. is measured by connecting the secondary winding, through a rotating commutator, to a Weston D. C. voltmeter. The brushes of this commutator can be shifted, and the reading of the Weston instrument is proportional to the flux at the instant of commutation. By shifting the brushes until the Weston reading is a

\footnotetext{
${ }^{3}$ Lloyd and Fisher, this Bulletin, 4, p. 467; I908. The rotating commutator was constructed in the instrument shop of the Bureau by Mr. F. E. Mann.
} 
maximum, the maximum value of the flux is measured. If at the same time the reading is taken upon a dynamometer voltmeter, the form factor of the emf. wave is thereby determined. By shifting the brushes until the Weston reading is a maximum, the maximum value of the flux is measured. If at the same time the reading is taken upon a dynamometer voltmeter, the form factor of the emf. wave is thereby determined. By shifting the brushes around, the successive values of the magnetic flux throughout the cycle can be read off and the wave form plotted. By connecting the commutator to the secondary of a mutual inductance whose primary is in the magnetizing circuit, the wave form of the magnetizing current may be similarly determined.

The rotating commutator is connected directly to the shaft of the generator, so that their phase relation is invariable. The generator is a four-pole, two-phase machine with surface-wound armature, and gives a sine wave. It is directly connected to a $\mathrm{D}$. C. motor, driven by current from a storage battery. A second generator, with I2 poles, is coupled to the same shaft and gives a frequency three times that of the first. The motor field circuit includes a rheostat in the laboratory, by means of which the speed can be adjusted. The speed is automatically recorded upon a chronograph by means of an electrical contact which is made once every hundred revolutions throngh the medium of a worm gear. This chronograph was made by the International Instrument Company, and is controlled by a standard clock so that its drum makes exactly one revolution per minute. The seconds are recorded upon the drum by the same fountain pen which registers the speed of the generator, the second marks falling in rows parallel to the axis of the drum. When the generator is making 900 revolutions per minute, corresponding to a frequency of 30 cycles per second, the speed marks are $62 / 3$ seconds apart, giving 9 marks to the minute. If the speed has been exactly adjusted, these marks also form rows parallel to the rows of second marks, and a glance at the drum is sufficient to show whether the speed is correct. Fig. 4 shows a sample record upon the chronograph. In all cases the speed was adjusted to give 30 or 60 cycles within o.I per cent before readings were taken, and consequently no corrections to the wattmeter or voltmeter readings are necessary on account of frequency. 
S

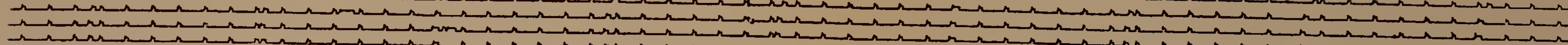
(n)

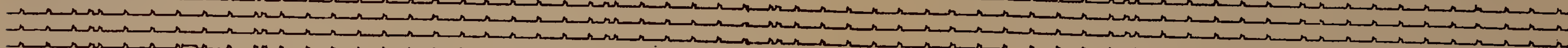

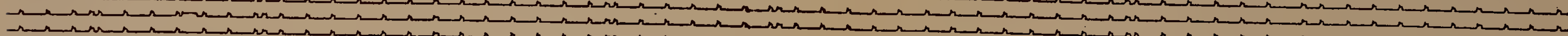
(n) (n)

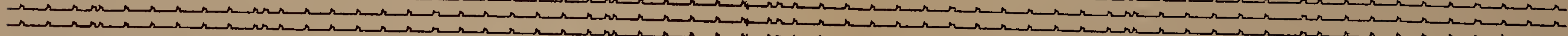
(n)

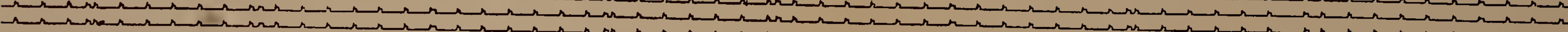
$r_{n}$

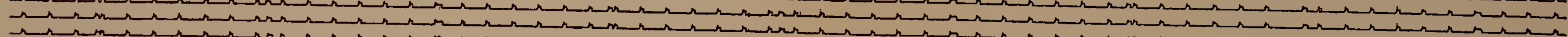

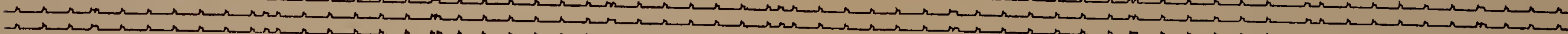
$\Omega_{n}$ $\rightarrow$ r

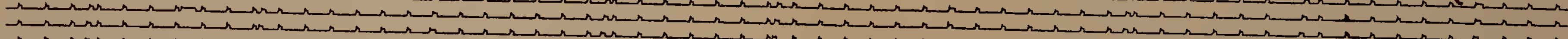

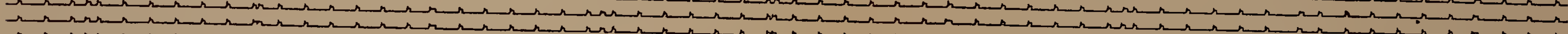
$r_{1}$ $\Omega$

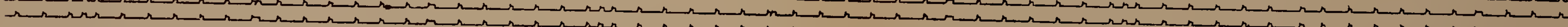
$\rightarrow$

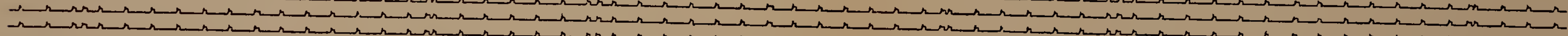

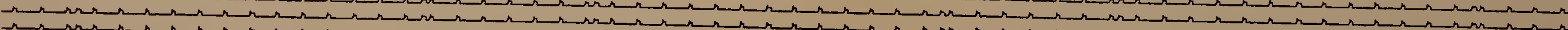

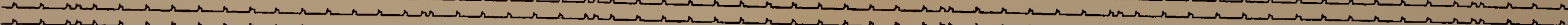

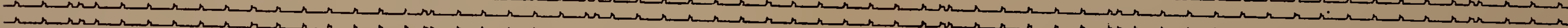
$\rightarrow$ $\rightarrow$ $\sim$ $r_{2}$ $\Omega$

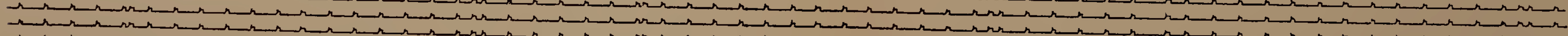

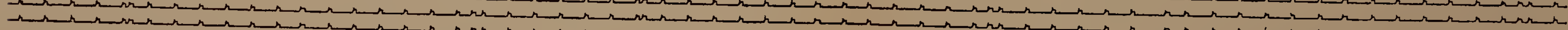
$\rightarrow$

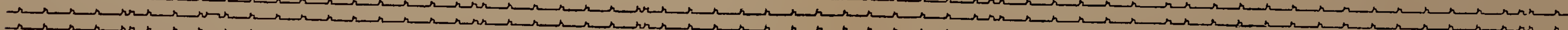
$\rightarrow r$

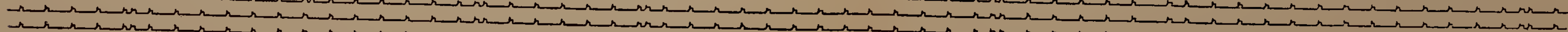
$\sim r$

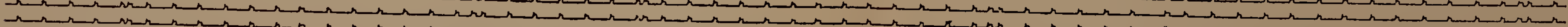

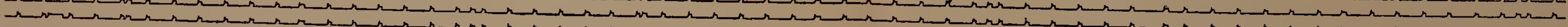

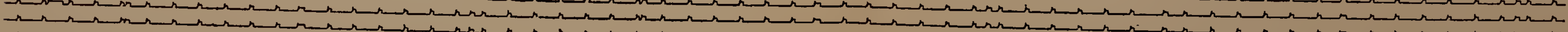

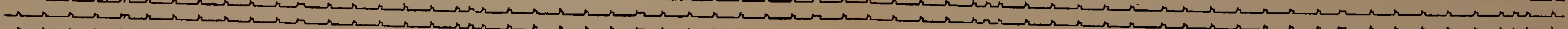

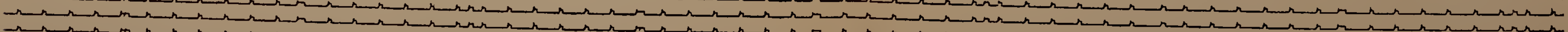
$\rightarrow$

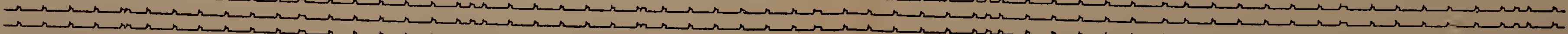

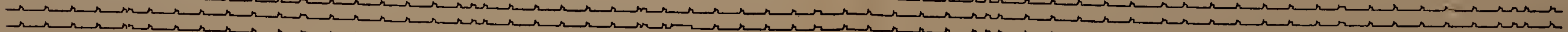
r

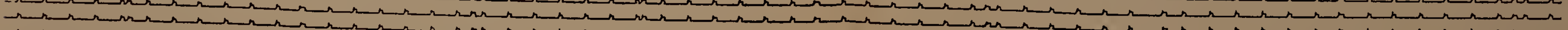

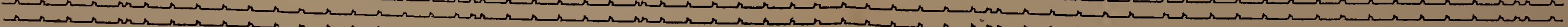

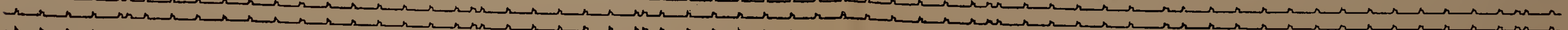

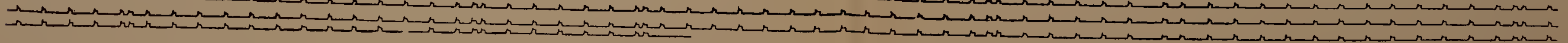

Fig. 4.

59629-08. (To face page 388.)

* Driving weight wound up. 
The generator field circuit also includes a rheostat in the laboratory, and this is used in adjusting the voltage to give the desired flux density. This makes it unnecessary to have an adjustable rheostat in the magnetizing circuit to control the current. A rheostat is always included in this circuit, however, in order to prevent a big rush of current when the circuit is first closed. After closing the circuit this resistance is reduced to zero, when it is desired to use a wave as nearly sinusoidal as possible. In other experiments

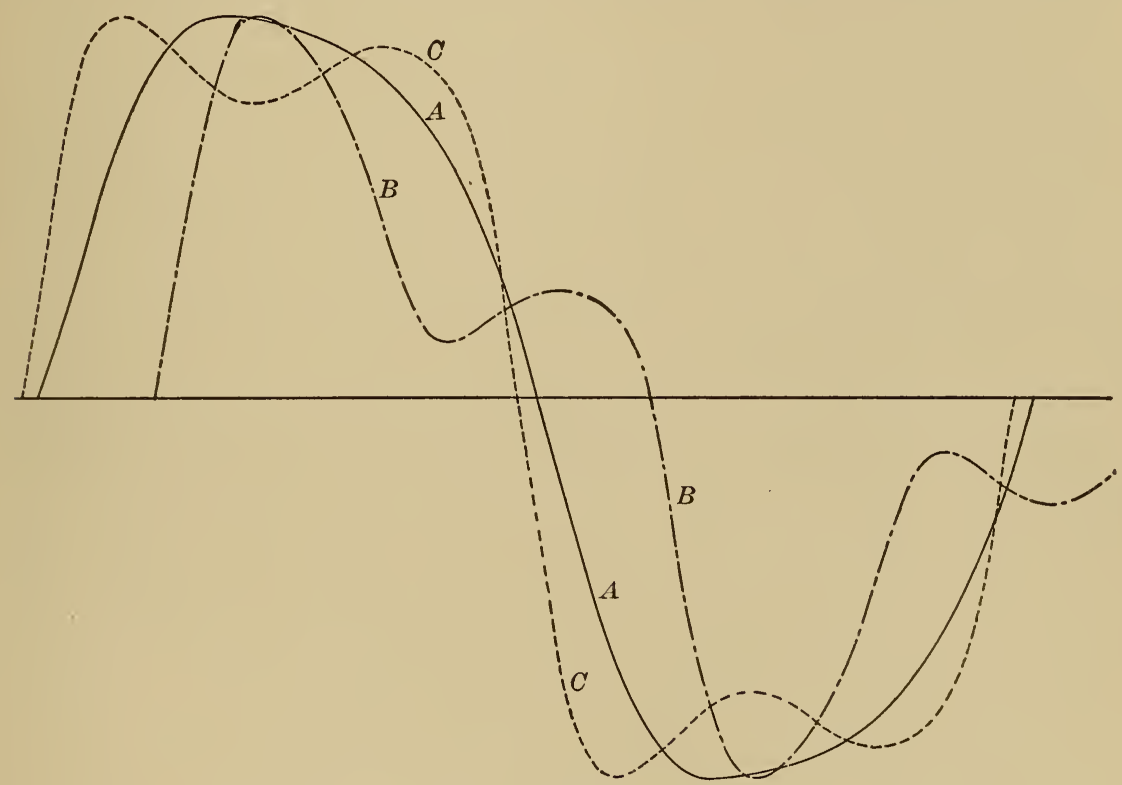

Fig. 5.-Flux Waves.

A. Undistorted wave for Experiments 8 and 9.

B. Distorted wave for Experiment 8.

C. Distorted wave for Experiment 9.

a large resistance was left in for the purpose of distorting the wave, which is conveniently done in this way. Distortion was also secured by connecting the second generator in series with the first and exciting it to a low voltage. Either phase could be used, and the terminals could be reversed, thus giving a wide range of wave forms, as will be seen from the illustrations and the tabulated form factors. 
The Weston voltmeter used is an especially sensitive instrument, giving a full scale deflection for a current of about 0.0004 ampere. This permitted the use of a high resistance in its circuit, making negligible any error due to its inductance, or to the variable resistance of the moving contacts on the commutator. The constants of the various specimens used in the experiments are as follows:

TABLE I.

\begin{tabular}{|c|c|c|c|c|c|c|c|c|c|c|}
\hline $\begin{array}{l}\text { Desig- } \\
\text { nation }\end{array}$ & Form & Material & $\frac{\stackrel{5}{5}}{3}$ & 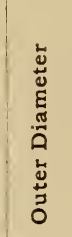 & 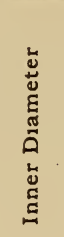 & 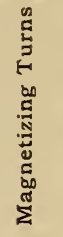 & 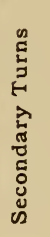 & 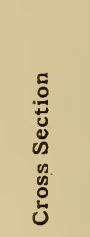 & 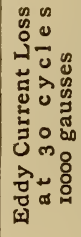 & 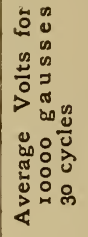 \\
\hline & & & grams & $\mathrm{cm}$ & $\mathrm{cm}$ & & & $\mathrm{sq} . \mathrm{cm}$ & $\begin{array}{c}\text { Per } \\
\text { cent }\end{array}$ & \\
\hline No. 28 & Ring & $\begin{array}{l}\text { Transformer sheet, } \\
0.033 \mathrm{~cm} \text { thick, not } \\
\text { annealed. }\end{array}$ & 199.5 & 8.9 & 6.9 & 102 & 320 & 1.048 & 14 & 4.023 \\
\hline No. 30 & “ & Same................. & 390.4 & 8.9 & 6.9 & 100 & 315 & 1.984 & 13 & 7.500 \\
\hline No. 31 & “ & Same, annealed ....... & 394.9 & 8.9 & 6.9 & 100 & 330 & 2.074 & 19 & 8.213 \\
\hline No. 36 & $“$ & $\begin{array}{l}\text { Iron wire, } 0.02 \mathrm{~cm} \\
\text { diam. }\end{array}$ & 185.5 & 11.0 & 8.3 & 260 & 414 & 0.795 & 1.5 & 3.950 \\
\hline No. 38 & “ & $\begin{array}{l}\text { Steel wire, } 0.005 \mathrm{~cm} \\
\text { diam. }\end{array}$ & 157.9 & 10.15 & 7.9 & 377 & 541 & 0.716 & 0.0 & 4.650 \\
\hline No. 41 & “ & $\begin{array}{l}\text { Transformer sheet an- } \\
\text { nealed, } 0.035 \mathrm{~cm} \text {. }\end{array}$ & 203.7 & 22.85 & 20.3 & 158 & 520 & 0.3865 & 19 & 2.412 \\
\hline No. 76 & “ & $\begin{array}{l}\text { Transformer sheet, } \\
0.059 \mathrm{~cm} \text { thick, not } \\
\text { annealed. }\end{array}$ & 316.8 & 22.85 & 20.3 & 352 & 500 & 0.601 & 20 & 3.606 \\
\hline G & $\begin{array}{l}\text { Epstein } \\
\text { Square }\end{array}$ & $\begin{array}{l}\text { Transformer sheet, } \\
0.033 \mathrm{~cm} \text { thick, not } \\
\text { annealed. }\end{array}$ & 1542 & & & 1000 & 180 & 1.950 & 7 & 4.218 \\
\hline W & 16 & $\begin{array}{l}\text { Transformer sheet, } \\
0.032 \mathrm{~cm} \text { thick, an- } \\
\text { nealed. }\end{array}$ & 765.6 & & & 700 & 700 & 0.493 & 28 & 4. 140 \\
\hline$S$ & " & $\begin{array}{l}\text { Common sheet iron, } \\
0.06 \mathrm{~cm} \text {. }\end{array}$ & 657.5 & & & 700 & 700 & 0.421 & 18 & 3.537 \\
\hline
\end{tabular}

\section{OBSERVATIONS.}

The first observations were taken in May, I907, soon after the rotating commutator was constructed. The method followed has already been indicated. Runs were taken at 30 and 60 cycles with as little distortion of wave as possible, the voltage of the generator being adjusted to give a definite flux density. The form factor of 
secondary electromotive force was determined in each case, and a separation of eddy current and hysteresis losses effected. The generator of triple frequency was then connected in series with the first, and runs taken at 30 cycles with distorted wave forms, the form factor being determined in each case. Usually the form of the flux wave was also plotted by taking readings on the Weston instrument while shifting the commutator brushes from point to point. If the flux wave should have a dimpled form, the experi-

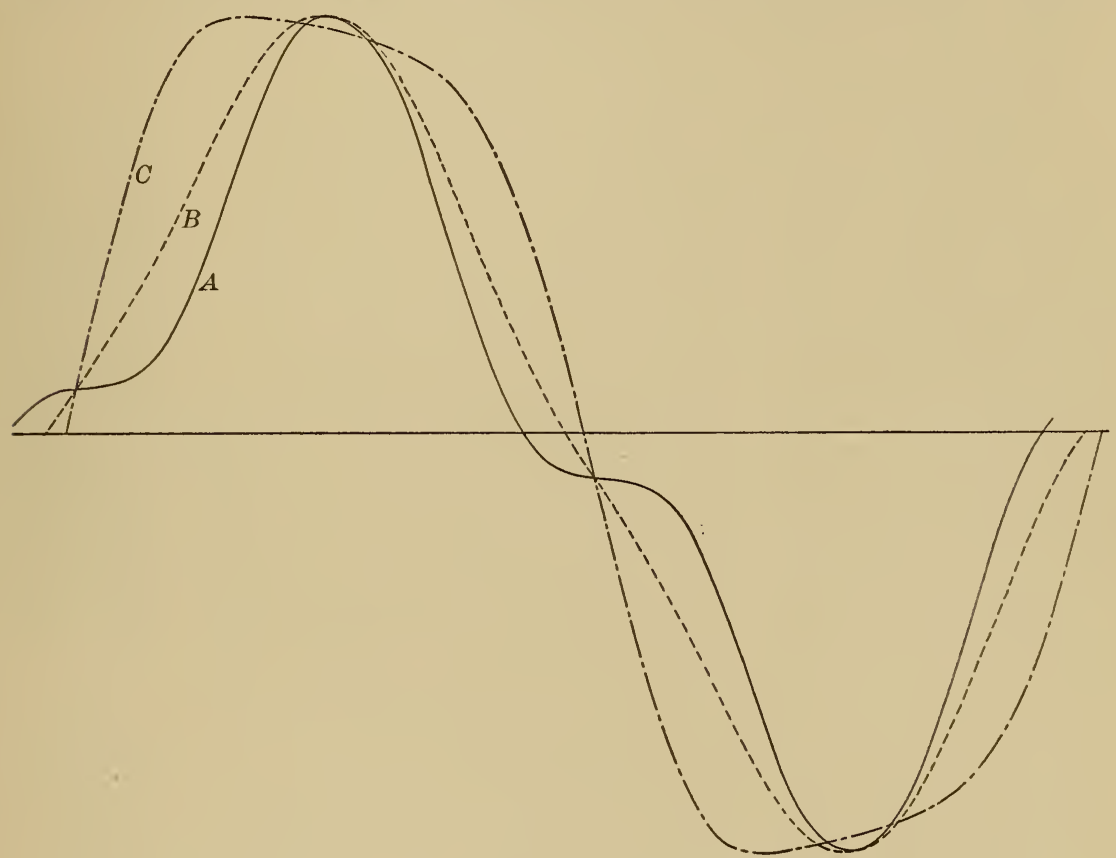

Fig. 6.-Flux Waves with Ring No. 31. $\quad B_{\max }=10000$ gausses. Experiments Nos. 19, 20, 21.

ment must be excluded from consideration, for this indicates that the iron has not been put through a simple hysteretic cycle, but a subsidiary loop has been included in the cycle, as shown in Fig. Io, dot and dash curve.

In such cases the energy is always greater than in the case of a single loop. Some cases of this kind are included in Table II and illustrated in the flux waves of Fig. 5. These results are bracketed, and are not to be considered as bearing upon the main problem. Flux waves were always platted when there seemed a possibility of 
TABLE II. (30 Cycles.)

\begin{tabular}{|c|c|c|c|c|c|c|c|c|}
\hline $\begin{array}{c}\text { Experi- } \\
\text { ment No. }\end{array}$ & Specimen & $\begin{array}{c}\text { Maximum } \\
\text { Density } \\
\text { (Gausses) }\end{array}$ & $\begin{array}{l}\text { Form } \\
\text { Factor } \\
\text { with } \\
\text { Undis- } \\
\text { torted } \\
\text { Wave }\end{array}$ & $\begin{array}{c}\text { Form } \\
\text { Factor } \\
\text { with } \\
\text { Dis- } \\
\text { torted } \\
\text { Wave }\end{array}$ & $\mid \begin{array}{c}\text { In- } \\
\text { crease } \\
\text { in Hys- } \\
\text { teresis } \\
(\text { Per } \\
\text { cent })\end{array}$ & Cause of Disto & ortion & $\begin{array}{l}\text { Type of } \\
\text { Flux Wave }\end{array}$ \\
\hline 1 & W & 5000 & 1.175 & 1.29 & +0.1 & \multirow{5}{*}{\multicolumn{2}{|c|}{$\begin{array}{c}\text { 3rd Harmonic } 11 \% \\
\text { ، }\end{array}$}} & \\
\hline 2 & W & 10000 & 1.26 & 1.22 & -0.9 & & & \\
\hline 3 & W & 10000 & 1.26 & 1.34 & +1.2 & & & \\
\hline 4 & W & 12000 & 1.32 & 1.27 & -1.1 & & & \\
\hline 5 & W & 12000 & 1.32 & 1.40 & 0.0 & & & \\
\hline 6 & $\mathbf{S}$ & 5000 & 1.28 & 1.21 & -0.2 & \multirow{5}{*}{\multicolumn{2}{|c|}{$\begin{array}{c}\text { 3rd Harmonic } \\
\text { "، }\end{array}$}} & \\
\hline 7 & $S$ & 5000 & 1.28 & 1.39 & +0.2 & & & \\
\hline 8 & $\mathbf{S}$ & 5000 & 1.29 & {$[1.52$} & $+2.2]$ & & & B Fig. 4 \\
\hline 9 & $S$ & 5000 & 1.29 & {$[1.74$} & $+-5.7]$ & & & C Fig. 4 \\
\hline 10 & No. 28 & 10000 & 1.54 & 1.17 & -1.3 & & & \\
\hline 11 & No. 28 & 10000 & 1.54 & 1.82 & +0.6 & \multicolumn{2}{|l|}{ 3rd Harmonic } & \\
\hline 12 & No. 30 & 10000 & 1.19 & 1.12 & +1.2 & “ & $21 \%$ & \\
\hline 13 & No. 30 & 10000 & 1.19 & 1.30 & -0.1 & “ & $21 \%$ & \\
\hline 14 & No. 30 & 10000 & 1.19 & 1.21 & +1.2 & “ & $63 \%$ & \\
\hline 15 & No. 30 & 10000 & 1.19 & 1.48 & +1.0 & “ & $63 \%$ & \\
\hline 16 & No. 31 & 10000 & 1.17 & 1.09 & +0.7 & \multicolumn{2}{|c|}{ 3rd Harmonic $27 \%$} & \\
\hline 17 & “ & 10000 & 1.17 & 1.35 & -2.0 & “ & $22 \%$ & \\
\hline 18 & “ & 7500 & 1.16 & 1.38 & +1.0 & “ & $30 \%$ & \\
\hline 19 & “ & 10000 & 1.165 & 1.20 & -0.5 & “ & $83 \%$ & A Fig. 5 \\
\hline 20 & “ & 10000 & 1.165 & 1.075 & -1.2 & “ & $30 \%$ & B Fig. 5 \\
\hline 21 & No. 31 & 10000 & 1.165 & 1.34 & 0.0 & \multicolumn{2}{|c|}{ 3rd Harmonic $26 \%$} & C Fig. 5 \\
\hline 22 & No. 41 & 10000 & 1.415 & 1.615 & -1.2 & “ & $24 \%$ & A Fig. 11 \\
\hline 23 & No. 41 & 10000 & 1.415 & {$[1.83$} & $\mid+1.2]$ & “ & $29 \%$ & Dimpled \\
\hline 24 & No. 76 & 10000 & 1.18 & 1.19 & -0.4 & “ & $29 \%$ & A Fig. 6 \\
\hline 25 & No. 76 & 10000 & 1.18 & 1.38 & +1.1 & “ & $31 \%$ & A Fig. 11 \\
\hline 26 & G & 10000 & 1.11 & 1.057 & -0.3 & \multicolumn{2}{|c|}{ 3rd Harmonic $23 \%$} & C Fig. 6 \\
\hline 27 & $“$ & 10000 & 1.11 & 1.292 & +0.3 & “ & $27 \%$ & D Fig. 7 \\
\hline 28 & “ & 10000 & 1.11 & 1.408 & +0.8 & “ & $46 \%$ & B Fig. 6 \\
\hline 29 & “ & 10000 & 1.11 & 1.069 & 0.0 & “ & $44 \%$ & C Fig. 6 \\
\hline 30 & “ & 5000 & 1.11 & 1.067 & -0.2 & “ & $44 \%$ & C Fig. 6 \\
\hline 31 & " & 5000 & 1.11 & 1.405 & +0.3 & “ & $46 \%$ & B Fig. 6 \\
\hline
\end{tabular}




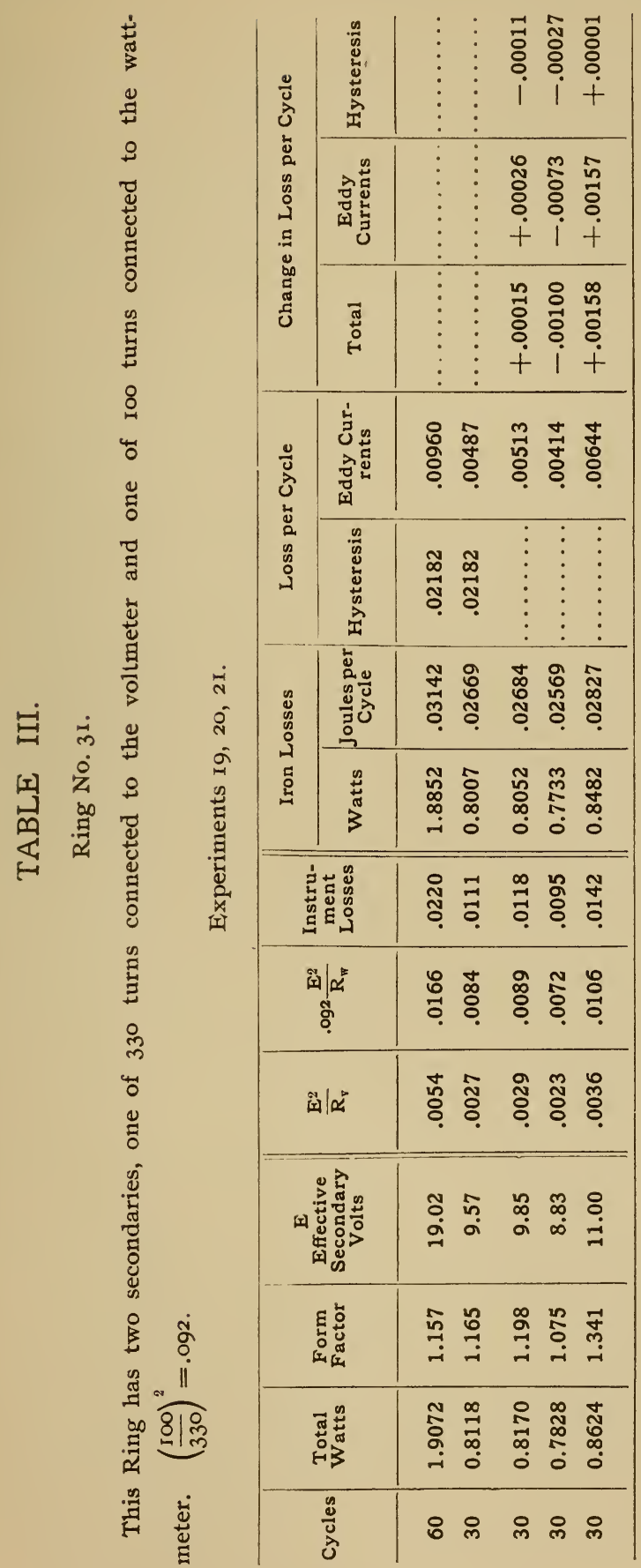


the wave being dimpled, and many later runs have been excluded from the tables on this account. When the distortion of wave is produced by resistance in the magnetizing circuit the wave is never dimpled, but has a characteristic shape, more or less pronounced, according to the magnitude of the resistance. Table II gives a summary of the results obtained at various times from May to December, 1907. Some of the wave forms are illustrated in Figs. 6 and 7 .

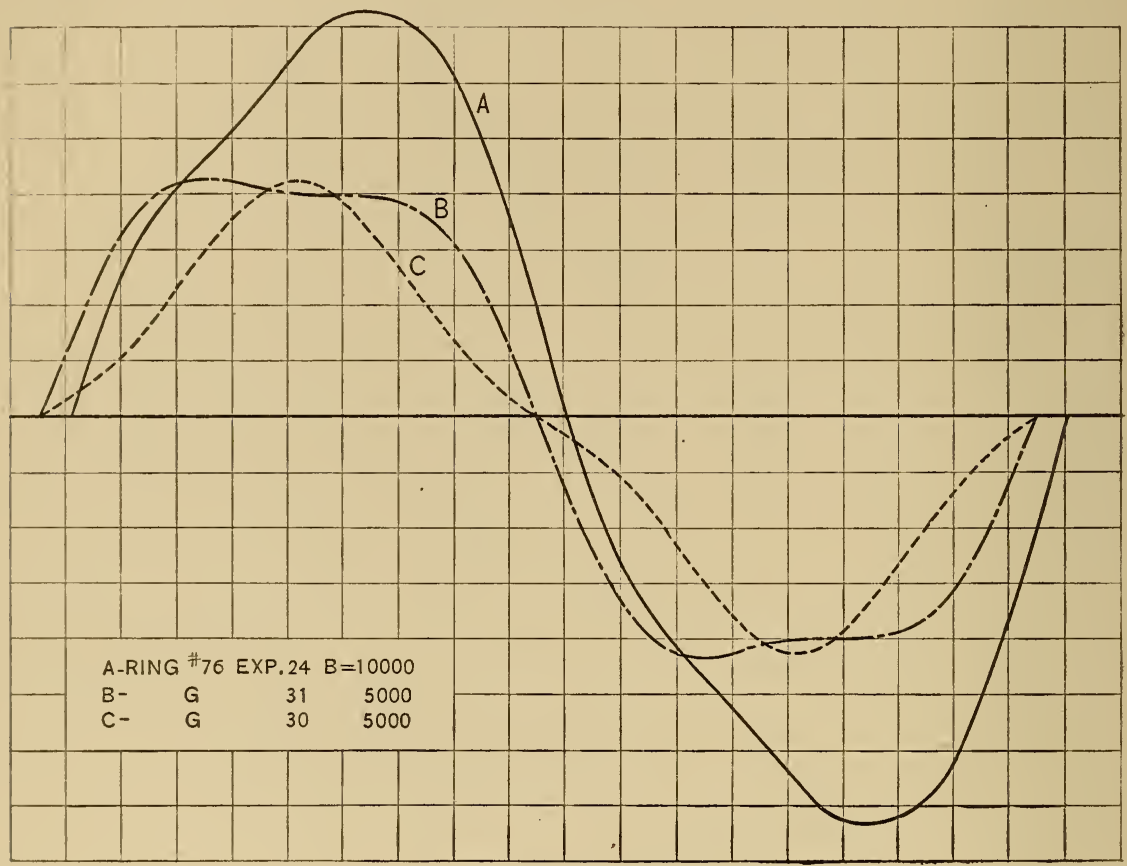

Fig. 7.-Flux Waves.

Table III is a sample of the observed values, with the method of computing results.

Next a ring was prepared from No. 36 iron wire with the idea of decreasing the eddy currents and thus making a more accurate separation of the two components of loss. The results obtained with this ring are given in Table IV and some of the flux curves illustrated in Fig. 8. The outstanding change in energy is here never more than I per cent, with a single exception. That the separation 
TABLE IV.-Ring No. 36.

AT 30 CYCLES.

\begin{tabular}{|c|c|c|c|c|c|c|}
\hline $\begin{array}{c}\text { Experi- } \\
\text { ment No. }\end{array}$ & $\begin{array}{c}\text { Maxi- } \\
\text { mum } \\
\text { Kilo- } \\
\text { gausses }\end{array}$ & $\begin{array}{c}\text { Form } \\
\text { Factor } \\
\text { with Un- } \\
\text { distorted } \\
\text { Wave }\end{array}$ & $\begin{array}{c}\text { Form } \\
\text { Factor } \\
\text { with } \\
\text { Distorted } \\
\text { Wave }\end{array}$ & $\begin{array}{l}\text { Increase in } \\
\text { Hysteresis }\end{array}$ & Cause of Distortion & $\begin{array}{l}\text { Type of Flux } \\
\text { Wave }\end{array}$ \\
\hline 32 & - & 1.149 & 1.119 & $\begin{array}{c}\text { Per cent. } \\
0.0\end{array}$ & 3rd Harmonic $46 \frac{1}{2} \%$ & B Fig. 7 \\
\hline 33 & 5 & 1.149 & 1.389 & +0.4 & “ & A Fig. 7 \\
\hline 34 & 5 & 1.161 & 1.249 & 0.0 & $10 \mathrm{Ohms}$ & B Fig. 8 \\
\hline 35 & 5 & 1.161 & 1.309 & +0.1 & $10 "$ & B Fig. 8 \\
\hline 37 & 10 & 1.193 & 1.379 & 0.0 & $10 \mathrm{ohms}$ & B Fig. 8 \\
\hline 38 & 10 & 1.193 & 1.482 & 0.0 & $20 "$ & B Fig. 8 \\
\hline 39 & 5 & 1.148 & 1.076 & +0.3 & 3rd Harmonic $28 \%$ & C Fig. 7 \\
\hline 40 & 5 & 1.148 & 1.248 & -0.2 & $26 \%$ & D Fig. 7 \\
\hline 41 & 5 & 1.148 & 1.426 & --0.6 & $750 \mathrm{hms}$ & B Fig. 8 \\
\hline 42 & 5 & 1.148 & 1.212 & -0.2 & $10 \mathrm{ohms}$ & B Fig. 8 \\
\hline 43 & 5 & “ & 1.249 & -0.3 & $20 "$ & " \\
\hline 44 & 5 & " & 1.346 & -0.5 & $30 " 6$ & “ \\
\hline 45 & 5 & “ & 1.406 & -1.0 & $70 "$ & " \\
\hline 46 & 5 & " & 1.441 & -1.0 & $100 "$ & $"$ \\
\hline 47 & 5 & " & 1.455 & -0.9 & $140 "$ & " \\
\hline 48 & 10 & 1.196 & 1.322 & 0.0 & $10 \mathrm{Ohms}$ & B Fig. 8 \\
\hline 49 & 10 & " & 1.420 & +0.1 & $20 "$ & “ \\
\hline 50 & 10 & " & 1.522 & +0.5 & $30 " 6$ & " \\
\hline 51 & 10 & " & 1.566 & +1.0 & 50 “ & " \\
\hline 56 & 10 & 1.204 & 1.324 & 0.0 & $100 \mathrm{hms}$ & B Fig. 8 \\
\hline 57 & 10 & “ & 1.477 & -0.3 & $25 \quad 6$ & “" \\
\hline 58 & 10 & " & 1.559 & -0.2 & 356 & “ \\
\hline 59 & 10 & " & 1.585 & 0.0 & 50 " & “ \\
\hline 60 & 10 & " & 1.663 & -0.2 & 65 " & “ \\
\hline
\end{tabular}

AT 60 CYCLES.

\begin{tabular}{l|r|r|r|c|cc|c}
36 & 5 & 1.145 & 1.234 & +0.3 & 20 & $0 \mathrm{hms}$ & B Fig. 8 \\
52 & 10 & 1.165 & 1.289 & +0.1 & 20 & " & " \\
53 & 10 & 1.165 & 1.415 & +0.3 & 40 “ & " \\
54 & 10 & 1.165 & 1.566 & +1.0 & 75 & “ & " \\
\hline 55 & 10 & 1.165 & 1.599 & +1.2 & 100 " & \\
\hline
\end{tabular}


of losses was not all that could be desired was shown in the following way. By trial, resistances were found whose introduction in the magnetizing circuit gave the same form factor for runs at 30 and 60 cycles. Separations were thus made at three form factors between I.I5 and I.3O, with a discrepancy in the results of I per cent.

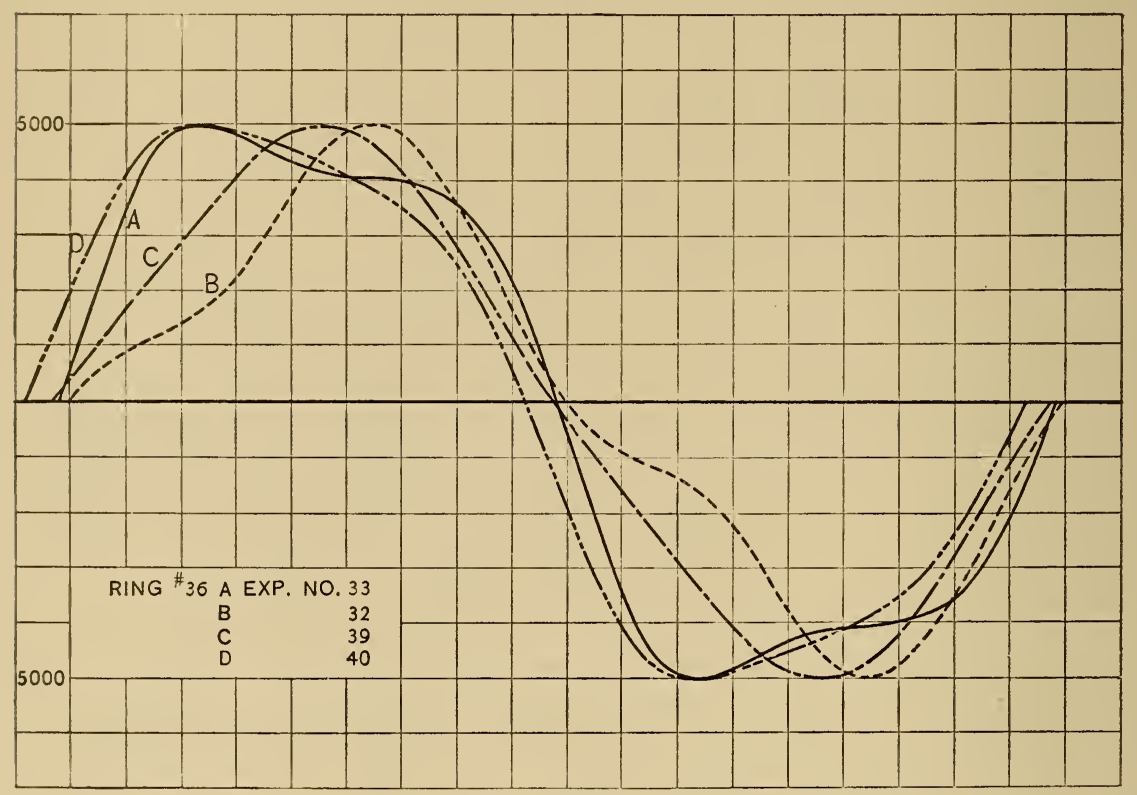

Fig. 8.-Flux Waves.

The next step was to obtain some soft steel wire 0.002 inch in diameter. This was soaked in shellac while being wound upon a brass form, and afterwards baked. It was then removed from the form and wound with magnetizing and secondary coils. The eddy current loss in this ring (No. $3^{8}$ ) was less than o.I per cent of the whole, and changes in the eddy current loss were negligible. A separation of the losses was therefore unnecessary. There was still a slight change in the instrument losses with form factor. This was small and easily computed, and if the change in wattmeter reading differed from this computed change it indicated a change in the hysteresis. These experiments are therefore the most conclusive of any. In each case the distorted wave was applied several times, 
intermediate readings being taken with undistorted wave, and unless the readings could be repeated the results have been discarded. It was usually necessary to have the current flowing for some time before the observations were taken, in order to reach an approximate equilibrium of temperature. In making changes it was endeavored to keep the flux density below the maximum used in setting. When through inadvertence it rose higher, the specimen was demagnetized by gradually reducing the magnetizing current. In making the final adjustments before reading, the maximum flux would necessarily vary slightly upon both sides of the desired setting. The results with this ring are given in Table $\mathrm{V}$ and some of the flux curves in Fig. 9. Table VI gives the details of experiment No. 67.

\section{TABLE V}

Ring No. 38, at 30 Cycles.

\begin{tabular}{|c|c|c|c|c|c|c|}
\hline $\begin{array}{c}\text { Experi- } \\
\text { ment No. }\end{array}$ & $\begin{array}{l}\text { Maxi- } \\
\text { mum } \\
\text { Gausses }\end{array}$ & $\begin{array}{c}\text { Form } \\
\text { Factor } \\
\text { with Un- } \\
\text { distorted } \\
\text { Wave }\end{array}$ & $\begin{array}{c}\text { Form } \\
\text { Factor } \\
\text { with Dis- } \\
\text { torted } \\
\text { Wave }\end{array}$ & $\begin{array}{c}\text { Increase in } \\
\text { Hysteresis } \\
\text { (Per cent) }\end{array}$ & Cause of Distortion & $\begin{array}{c}\text { Type of } \\
\text { Flux Wave }\end{array}$ \\
\hline 61 & 5000 & 1.145 & 1.320 & 0.0 & 3rd Harmonic $25 \%$ & A Fig. 8 \\
\hline 62 & 5000 & 1.168 & 1.407 & +0.35 & $50 \mathrm{Ohms}$ & B Fig. 8 \\
\hline 63 & 5000 & 1.153 & 1.365 & 0.0 & 35 ، & B Fig. 8 \\
\hline 64 & 5000 & 1.157 & 1.328 & 0.0 & 3rd Harmonic $25 \%$ & C Fig. 8 \\
\hline 65 & 2500 & 1.124 & 1.254 & +0.1 & $55 \mathrm{ohms}$ & B Fig. 8 \\
\hline 66 & 5000 & 1.162 & 1.363 & +0.85 & 39 " & B Fig. 8 \\
\hline 67 & 5000 & 1.155 & 1.442 & +0.9 & 80 " & B Fig. 8 \\
\hline 68 & 10000 & 1.187 & 1.653 & +0.4 & 54 “ & B Fig. 8 \\
\hline 69 & 10000 & 1.190 & 1.422 & +0.3 & 3rd Harmonic $34 \%$ & A Fig. 7 \\
\hline
\end{tabular}

Energy Loops.-By taking readings of the instantaneous values of both magnetizing current and flux through a cycle, it is possible to plat these values so as to form a closed loop whose area is a measure of the energy expended by the current. This energy is due to hysteresis, to eddy currents, and to the copper loss in the secondaries. The latter can be made very small by breaking the potential circuit of the wattmeter, leaving only the high resistance Weston voltmeter as a secondary load. As indicated in Table VI, this would 
ordinarily be not more than one-fourth per cent of the total energy. The total-iron loss can be obtained in this way, but there is no means of separating the two components.

Such loops have been platted for Rings 36,38 , and 4 I. Fig. Io shows several half loops for No. 4I, only two of which have been drawn in full, the important parts of the others alone being indicated. Fig. I I shows similar results for No. 36, and Fig. I 2 gives the forms of the waves of current and flux. In each case, for the loop at 60 cycles, the readings near the maximum values have been

\section{TABLE VI.}

Details of Experiment No. 67.

Ring No. 38 , at 30 cycles and 5000 gausses.

\begin{tabular}{c|c|c|c|c}
\hline Extra Resistance & Brush Setting & $\begin{array}{c}\text { Wattmeter } \\
\text { Deflection }\end{array}$ & Effective Volts & Form Factor \\
\cline { 2 - 3 } Ohms & Degrees & $\mathrm{cm}$ & & \\
80 & 70 & 20.91 & 3.354 & 1.442 \\
0 & 89 & 20.59 & 2.687 & 1.155 \\
80 & 69 & 20.86 & 3.351 & 1.441 \\
0 & 89 & 20.59 & 2.687 & 1.155 \\
\hline
\end{tabular}

Change $=0.29 \mathrm{~cm}$.

Weston reading for average volts $=2.325$.

Weston resistance $=7885$ ohms.

Wattmeter resistance $=2000$ ohms.

Instrument losses $=(2.687)^{2}\left(\frac{\mathrm{I}}{7885}+\frac{\mathrm{I}}{2000}\right)=0.0045$ watts.

$$
\left(\begin{array}{l}
1.442 \\
\text { I. } .155
\end{array}\right)^{2} 0.174=0.27 \mathrm{~cm} . \quad \text { Change }=0.10 \mathrm{~cm} 1 .
$$

Increase in hysteresis $=0.19 \mathrm{~cm}=0.9 \%$.

NoTE.-The dynamometer voltmeter is disconnected while wattmeter is read.

taken at closer intervals and platted to a much larger scale in the upper left-hand corner. These show distinctly that the current reaches a maximum before the flux. The elapsed time between the maxima is, in the case of No. $4 \mathrm{I}$, equal to $0.00028 \mathrm{sec}$. or $\mathrm{I} .7$ per cent $(\mathrm{r} / 60)$ of the time of a complete cycle; for No. 36 it is 0.00014 sec. or 0.8 per cent of the time of a cycle. A similar condition 
could not be established with certainty for No. 38 , although a slight difference in phase between the two maxima was indicated.

Hysteresis loops for these same rings have been determined by using the ballistic method with direct currents, and these results also are platted in the figures. The area of these ballistic loops has been determined, and the energy compared with the wattmeter measurements.

\section{TABLE VII.}

Comparison of Hysteresis Measurements by Wattmeter and Ballistic Methods.

\begin{tabular}{|c|c|c|c|c|c|}
\hline \multirow{3}{*}{ Ring } & \multirow{3}{*}{$\begin{array}{c}\text { Maximum } \\
\text { Flux Density B }\end{array}$} & \multicolumn{3}{|c|}{ Hysteresis } & \multirow{3}{*}{$\begin{array}{c}\text { Exponent } \\
\text { of } B \\
\text { (Ballistic) }\end{array}$} \\
\hline & & \multicolumn{2}{|c|}{ Ergs per $\mathrm{cm}^{3}$ per cycle } & \multirow{2}{*}{ Difference } & \\
\hline & & Wattmeter & Ballistic & & \\
\hline & Gausses & & & Per cent & \multirow{3}{*}{1.78} \\
\hline 41 & 5000 & 1318 & 1310 & 0.6 & \\
\hline 41 & 10000 & 4722 & 4500 & 4.7 & \\
\hline 36 & 5000 & 4750 & 4540 & 4.3 & \multirow{2}{*}{1.56} \\
\hline 36 & 10000 & 14100 & 13370 & 5.2 & \\
\hline 38 & 2500 & 4547 & 4548 & 0.0 & \multirow{4}{*}{$\begin{array}{l}1.56 \\
1.34 \\
1.35\end{array}$} \\
\hline 38 & 5000 & 13380 & 13380 & 0.0 & \\
\hline 38 & 10000 & 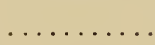 & 33910 & & \\
\hline 38 & 15000 & 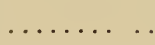 & 58720 & & \\
\hline
\end{tabular}

With Ring No. 38 the loops obtained (for maximum of 10000 gausses) by the two methods agreed within the error of observation. The hysteresis loss, as determined by the wattmeter, was the same for this ring as when determined by the ballistic method. Table VII gives a comparison of the results by the two methods. The power of $B$ to which the loss is proportional is also indicated, and it is apparent that this may be quite different in different specimens, as well as varying with the flux.

I am indebted to Dr. C. W. Burrows for the measurements with the ballistic galvanometer, and to Mr. J. V. S. Fisher for assistance in the work with alternating currents.

$$
59629-08-5
$$




\section{DISCUSSION OF THE RESULTS.}

The first results obtained appeared to indicate a definite dependence of hysteresis upon the wave form. The differences obtained were much greater than could be accounted for by errors in taking the readings. The settings on the Weston voltmeter could be made to within O.I per cent, and the other instruments could be read more accurately than this. Indeed, in magnetic work, it seems useless to strive for great precision in reading, since conditions can not be duplicated as closely as instruments can be read. It is well known that the present magnetic condition depends upon certain features of its past treatment, and it would seem to depend upon some others

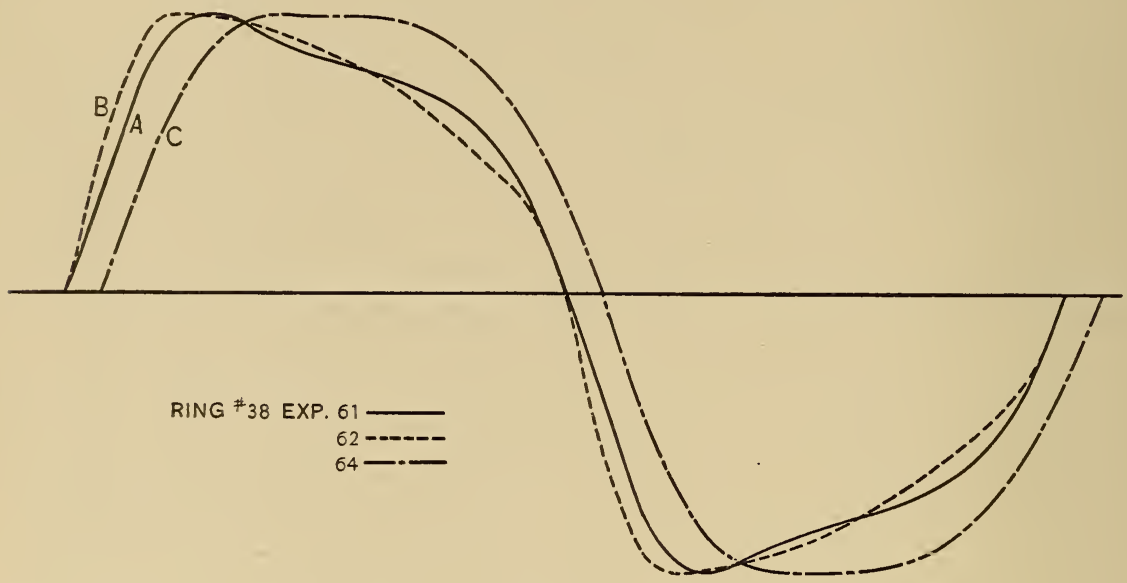

Fig. 9.-Flux Waves. $B_{\max }=5000$ gausses.

that are not so well known. After a specimen has been highly magnetized, the hysteresis loss at a lower induction will depend upon whether it has been subsequently demagnetized. This is well recognized in ballistic work, but it seems to be disregarded in magnetization with alternating current, where its influence, nevertheless, is just as potent. A transformer which has been tested at double voltage may continue for years to consume more energy than would be necessary if it were afterwards demagnetized. Even when demagnetization is resorted to, and the temperature maintained within narrow limits, the iron losses do not seem to return consistently to a previously determined value, and measurements made under condi- 
tions supposedly identical do not yield results in as close agreement as o.I per cent. The accuracy of the instruments used in this research therefore seems more than sufficient. In the final experiments care was taken to avoid disturbing influences, and unless readings could be repeated within one-fourth per cent when changing

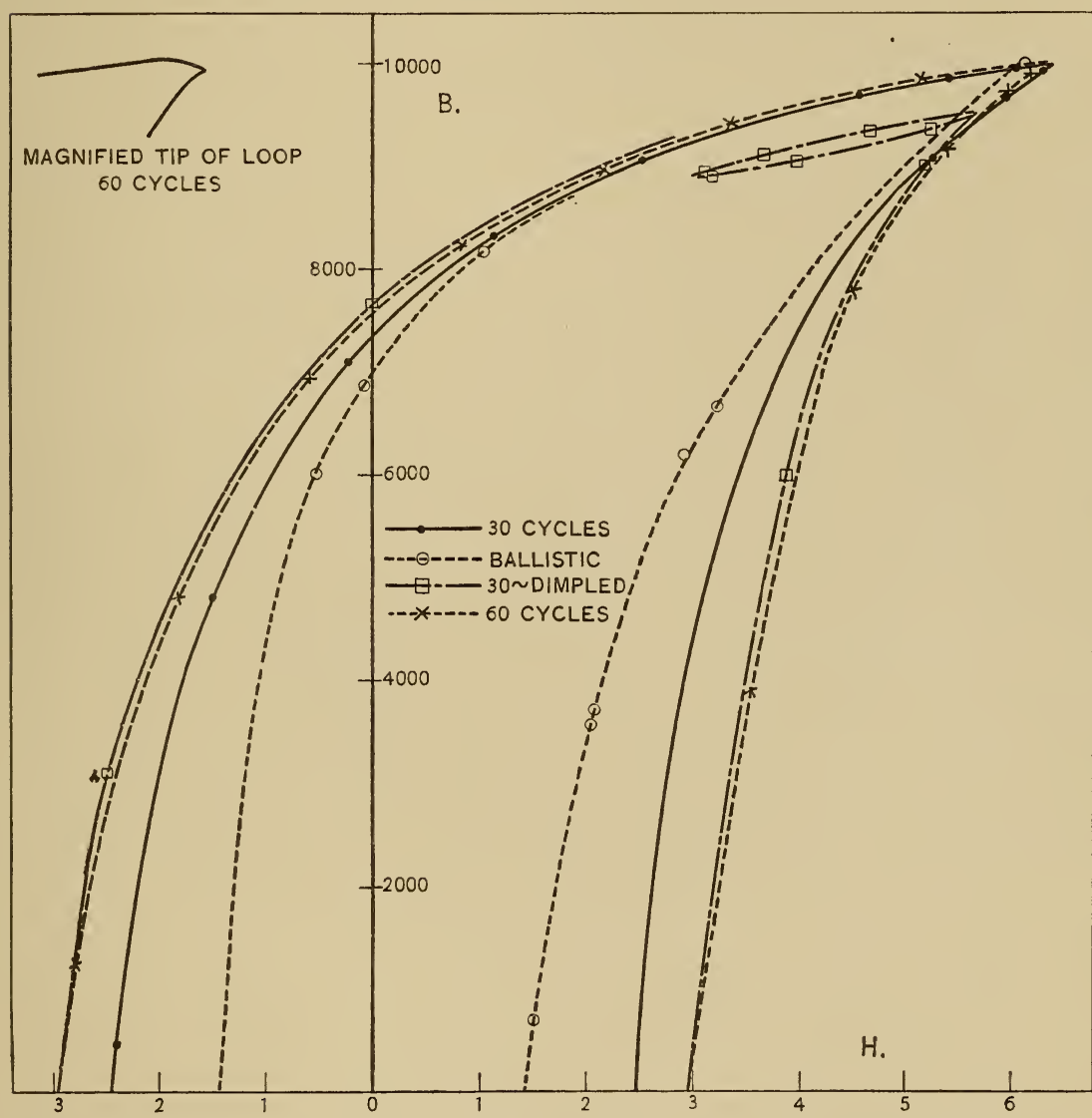

Fig. 10.-One half of Energy Loops with direct current and with different wave forms of alternating current. Ring No. 41. $B_{\max }=10000$ gausses.

from one wave to another and back, they were discarded. Table VI illustrates that this could be done. In the earlier experiments, however, this repetition was not required, and many of the results given are from single observations. Temperature effects, however, were avoided by changing quick! 1 from one wave form to another. 
[ Vol. 5, No. 3.

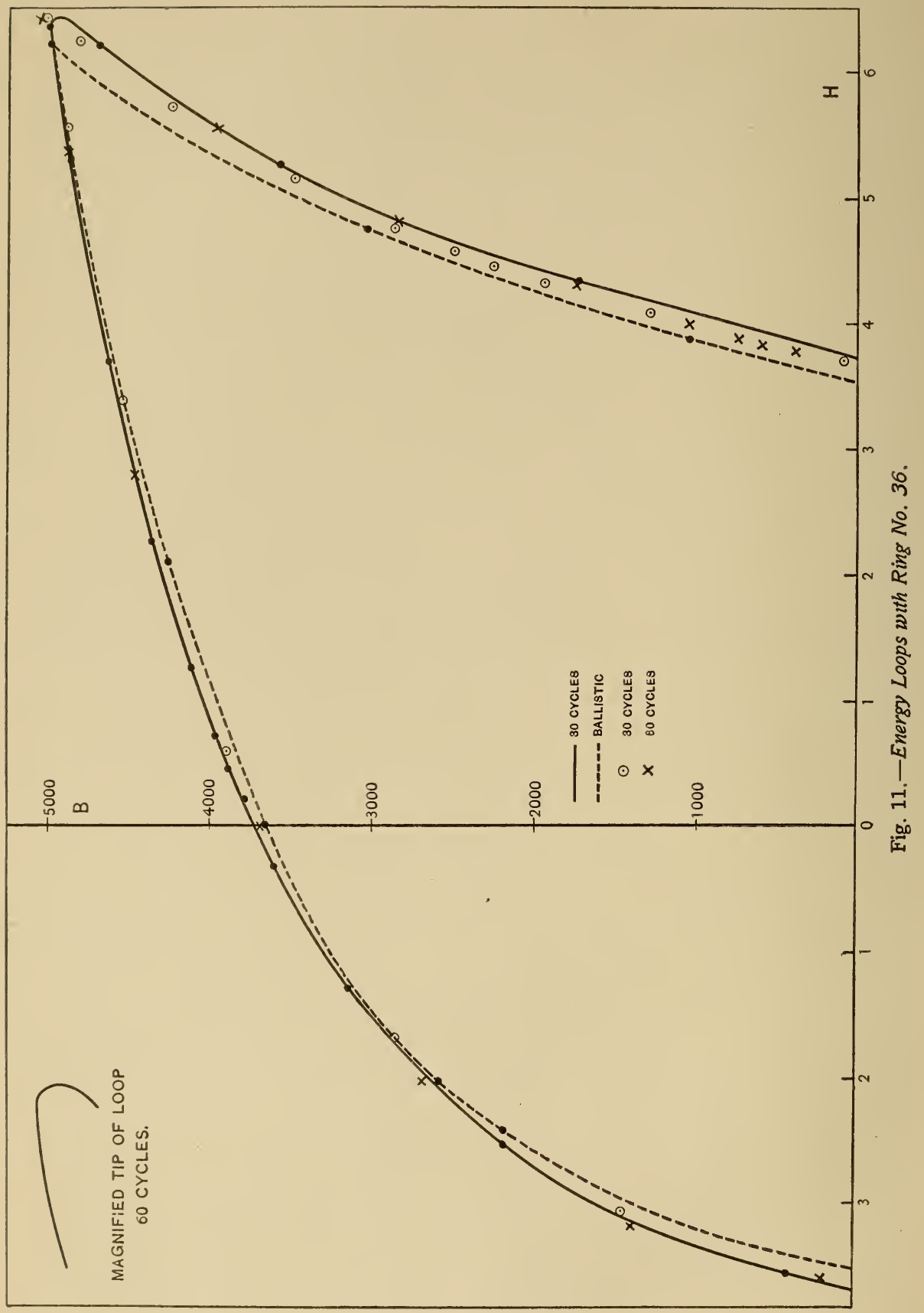




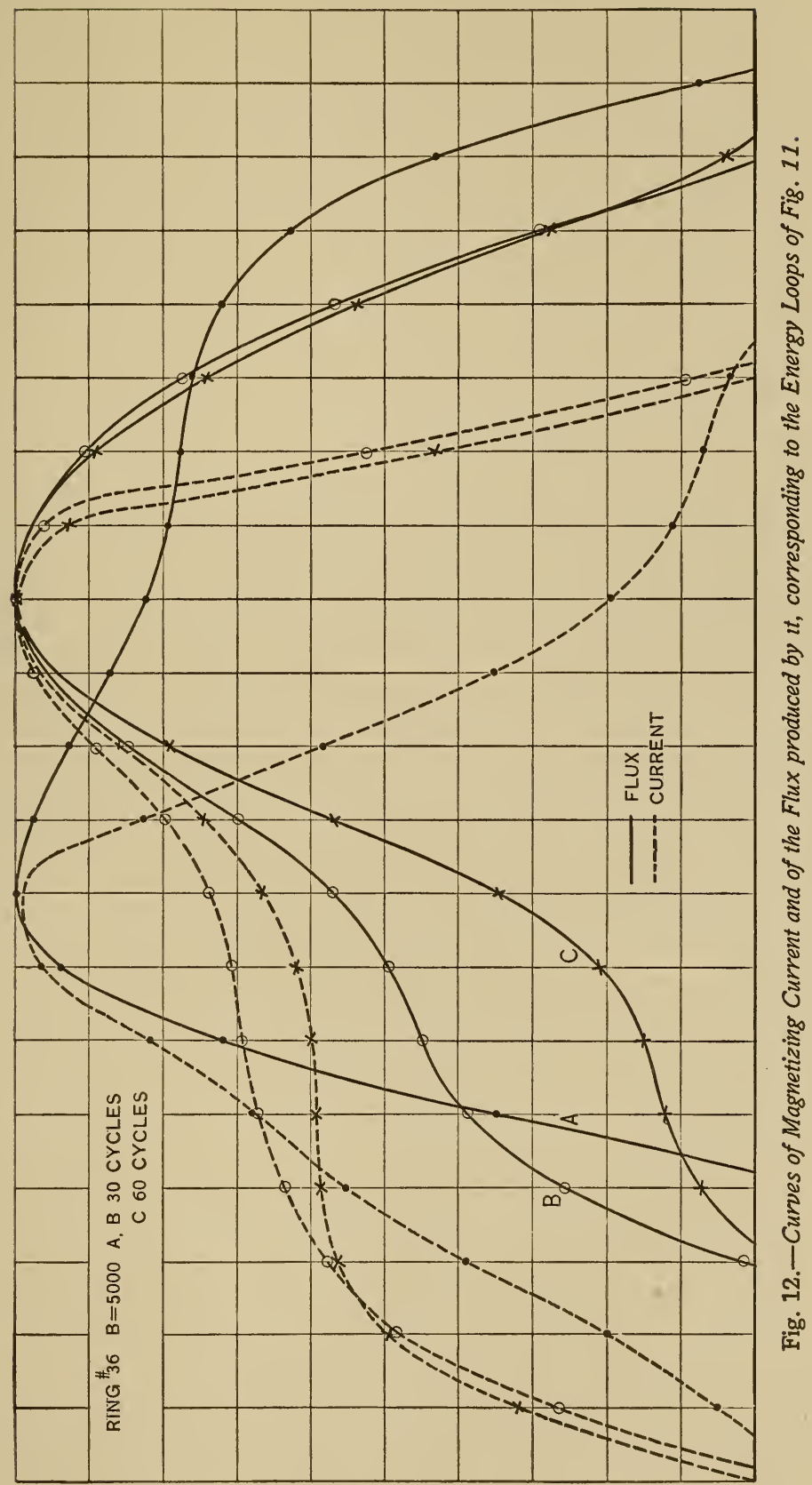


When the distorted wave gave a secondary electromotive force with form factor lower than that used for the separation of the losses, the hysteresis appeared smaller; when the new form factor was higher, the hysteresis appeared larger. The eddy current loss formed a goodly portion of the total in all of these early specimens, however, and there was the uncertainty of the separation to be considered, especially since the computed changes in hysteresis were all under 2 per cent. Moreover, the direction of change above noted was not maintained in all cases with the ring specimens.

With Ring No. 36 the eddy current loss was a very small part of the whole, and the indicated changes at once were confined to a limit of I per cent (with a single exception at I. 2 per cent). In experiments Nos. 48 to $5 \mathrm{I}$ at 30 cycles and Nos. 52 to 55 at 60 cycles, there seemed to be a progressive change evident with increasing distortion; yet these results are in contradiction to those of experiments Nos. 56 to 6o, and in the opposite sense to those of Nos. 42 to 47 at a different induction. The variations in hysteresis appear, then, rather accidental than systematic.

Turning to Table V, the results with Ring No. 38 can not be attributed to eddy currents. The whole question hinged here upon whether the observed change in wattmeter reading was accounted for by the change in instrument losses. In three cases it was so accounted for, but in others it was unmistakably not so accounted for, and the change in hysteresis seems positive. The change is in the direction first noted; that is, the hysteresis increases with the form factor of induced electromotive force. In other words, a flat flux wave causes a higher value for the hysteresis loss than a sinusoidal or peaked wave. No relation between the quantitative value of the effect and the amount of distortion of the wave is evident. The effect may be explained on the basis of a magnetic viscosity. If the flux values lag behind the corresponding values of magnetizing force, then the hysteresis loop will be broader for a flat flux wave, since the change through the zero values is more rapid. This explanation would require also a higher value of the hysteresis with higher frequency.

The comparison of the ballistic and the wattmeter measurements shows that the latter sometimes gives a larger value for the hysteresis. In Ring No. 38, however, where all uncertainty due to eddy currents 
has been eliminated, there is no difference; and even with Ring No. $4 \mathrm{I}$, where the eddy currents are of considerable magnitude, the discrepancy does not exceed 5 per cent. This is in contradiction to the results of Lyle, Niethammer, and others, but confirms the work of Gumlich and Rose. ${ }^{4}$

In Figs. Io and II it is noticeable that where the plotted points for any curve lie close together, indicating that at this part of the cycle the changes were proceeding slowly, the curve is here also closer to the ballistic curve, since the influence of eddy currents is minimized. In Fig. Io the dot-and-dash line represents a cycle with a dimpled flux wave, and it consequently forms a subsidiary loop, the completion of this small loop occupying about half the time of a half cycle. Consequently the remaining part of the half cycle must also be completed in half the time, and the consequence is that the values for this 3 -cycle loop are changing at about the same rate as for a 6o-cycle loop. Inspection of the figure shows that the points fall very close to the curve obtained at 60 cycles, and both of these are much farther from the ballistic loop than the normal curve for 30 cycles (solid line).

In the case of both Rings Nos. 36 and 4I the maximum magnetizing force (externally applied) with alternating current is considerably larger than the maximum used in the ballistic test to obtain the same flux density. This is due to the eddy currents, which exert a demagnetizing force, and part of the nominal magnetizing force is necessary to neutralize this field. Consequently computations of permeability based on such values would yield spurious results. In the case of Ring No. 38 such a difference between the magnetizing forces in the two cases was not observed, and the permeability was apparently as high with alternating as with direct current.

\section{DISCUSSION OF PREVIOUS INVESTIGATIONS.}

The problem of the effect of wave form upon hysteresis has been attacked by several investigators, and the closely related problem of the effect of frequency by a great many more.

${ }^{4}$ E. Gumlich and P. Rose, Electrot. Zs., 26, p. 503; 1905. 
Niethammer ${ }^{5}$ has obtained the most remarkable results with respect to wave form. He measured the power consumed with a wattmeter, and computed the maximum flux density from the average electromotive force, determined by plotting the wave of electromotive force. The two components of loss were separated by taking observations at two frequencies ( 37 and 59 cycles). In a ring built up of sheet iron, he observed a decrease in the hysteresis with a peaked emf. wave as compared with the value with an approximately sinusoidal wave. The form factors are not given, but the wave forms used are illustrated in another article. ${ }^{6} \quad$ The difference in hysteresis amounted to I6 per cent at 2300 gausses, and to over 30 per cent at 13300 gausses. It is to be noted that the curves taken are not of secondary emf., but of primary emf. The resistance of the magnetizing coil is not given, so that it is not possible to judge whether the ohmic drop in this winding would seriously affect the wave form or the voltage reading from which flux density is computed. Evidently no allowance is made for either of these possible sources of error, and it is assumed that the wave form is the same at different frequencies. Even so, it does not seem probable that they could account for differences as large as those observed. It is to be noticed also that he found the hysteresis with alternating current larger by about 20 per cent than the hysteresis obtained by a static method.

Benischke, ${ }^{7}$ on the other hand, found the hysteresis increased by a peaked wave of electromotive force, and decreased by a flat wave. His results carry little weight, however, as they are vitiated by the use of an incorrect relation between the maximum flux density and the observed effective voltage. He, too, made no allowance for the ohmic drop in the magnetizing coil, and did not read the voltage at the time of observation, measuring the watts with voltmeter disconnected, and consequently with a voltage different from that recorded.

Krogh and $\mathrm{Rikli}^{8}$ measured the total iron losses in ring specimens by the wattmeter method, and computed the eddy current loss

\footnotetext{
${ }^{5}$ F. Niethammer, Wied. Ann., 66, p. 29; I 898.

${ }^{6}$ Electrot. Zs., 19, p. 669; 1898.

${ }^{7}$ G. Benischke, Electrot. Zs., 22, p. 52; I90I: Discussion, pp. III, I85, 267, 3 I3. Ibid., 27, p. 9; Igo6: Discussion, pp. 235, 236.

${ }^{8}$ Krogh and Rikli, Electrot. Zs., 21, p. 1083 ; 1900.
} 
from theoretical considerations. The remainder was assumed to be due to hysteresis, and this showed an increase with the form factor of the applied emf. and also with the frequency. The change between form factors of I.II and I.I6 amounted to about 2 per cent at 5000 gausses and 50 cycles per second. There are three objections to accepting their results. The method of measuring the flux density is not given. The ratio of outer to inner diameter of the rings was I.55, so that there was an enormous variation of flux density over the cross section of the material. ${ }^{9}$ Finally, the eddy current loss, which in the case cited amounted to a fifth of the total loss, is not measured but cornputed from a formula, and hence uncertain.

Sahulka ${ }^{10}$ used a half-period contact ring (same principle as used by me) for determining average emf. and thereby the correct flux density, and found an increased loss when using a wave similar to that shown in Fig. 6, Curve A. He used a ring composed of insulated wires, $0.018 \mathrm{~cm}$ in diameter, in which he assumed that the eddy currents were negligible, regardless of the fact that the loss per cycle increased with the frequency. No numerical results are given, and without further details it does not seem fair to assume that the increased loss was not due to eddy currents. The form factor of the secondary emf. induced by the given flux wave would be greater than for a sine curve, and both eddy current loss and instrument losses would be increased by using such a wave.

The form of wave used in one of their researches was varied by Gumlich and Rose ${ }^{11}$ so that the form factor of electromotive force had values from I.06 to I.I9. The resulting change in iron losses was fully accounted for by the change in eddy currents within the accuracy of the observations, which was about 2 per cent.

The effect of frequency has received a great deal more attention, both by earlier and more recent investigators. The earlier researches were largely faulty in method and contradictory in results, and as they have been discussed by Wien ${ }^{12}$ it is not necessary to consider them here. The work of Wien was undoubtedly the most pains-

${ }^{9}$ Cf. this Bulletin, 5, p. 435; 1909.

${ }^{10}$ J. Sahulka, Electrot. Zs., 28, p. 986; 1907.

11 E. Gumlich and P. Rose, Electrot. Zs., 26, p. 403; r905: Discussion, pp. 500, 576.

${ }^{12}$ M. Wien, Wied. Ann., 66, p. 859; 1898. 
taking and thorough which had been done up to that time, and his method was ingenions. He measured the change in effective resistance and inductance of the magnetizing circuit by a bridge method, using a sinusoidal current. Equations were derived connecting the energy, the permeability, and the flux with these, and with the magnetizing current, from which also the magnetizing force could be computed. Neither flux nor energy was measured directly. Since the magnetizing current was sinusoidal, the flux was far from sinusoidal, especially at high inductions, and corrections had to be made for the resulting harmonics in the eddy currents. The reduction in maximum flux density by the demagnetizing effect of the eddy currents was allowed for, but never amounted to more than 2.7 per cent, and was negligible in the small wires. The worst error of observation was of about the same magnitude. Small rings of wire were experimented upon and the results compared with static measurements by the ballistic method. Changes as great as 70 per cent in the hysteresis of soft iron at the same high flux density were computed for a frequency of 520 cycles. Smaller proportional effects were obtained at lower frequencies and with harder steel, but the absolute values of the changes with the latter were just as large as with the soft iron.

It is greatly to be regretted that the care and energy given to this work were not expended in the direct measurement of the quantities involved. The values of flux density used in comparison here are the values computed for the maximum of the fundamental component of the flux wave, and since the harmonics were very prominent this probably is quite different from the maximum value for the actual wave, which has not been determined. The eddy current corrections, due to the harmonics of the flux wave, are large and uncertain, and it would seem in consequence of these two facts that the numerical values of Wien are not reliable. It seems hardly likely, however, that the entire effect found by him could be thus explained, and his conclusion seems justified, that at high frequencies the magnetization can not follow the magnetizing force quickly enough to reach the values obtained with direct current, making the iron appear harder. 
Lyle ${ }^{13}$ has also found that the hysteresis with alternating currents is greater than that measured by a ballistic test, and that it increases with the frequency. His method consisted in platting the curves of flux and magnetizing current, analyzing these, and computing the energy from the elements. The highest frequency used was 50 cycles, and the magnitude of the effect claimed (at this frequency and Ioooo gausses) is about 30 per cent of the ballistic loss. He, like Wien, aimed to secure a sinusoidal magnetizing current, with the result that the flux wave was very much distorted, and the results may be interpreted as a change in hysteresis with wave form just as properly as a change with frequency. The one condition was not held constant while the other was varied, and consequently the effects of the two can not be separated. The correction for energy expended in eddy currents varies in amount from 0.7 to 2 times the frequency effect claimed, yet this correction is based entirely upon a computed estimate and not upon any experimental determination. The formula given by Lyle as expressing the relation between total loss per cycle, frequency and magnetic induction, is not in terms of the maximum magnetic induction, but what he calls the "effective" induction, which is the maximum induction which, with a sine wave, would induce the same effective voltage as the actual wave. Moreover, there is no separate term for eddy current loss, this being combined with the frequency term of the hysteresis loss to give about I. 5 per cent change per cycle. The author points out himself that this formula holds only when the wave of magnetizing current is sinusoidal; it is, then, of very limited application.

In direct contradiction to Wien and Lyle are the results of Maurain, ${ }^{14}$ of Williams and Kaufmann, ${ }^{15}$ of Guye, Herzfeld, and Schidlof, ${ }^{16}$ and of Batelli and Magri. Maurain determined the curve of induced electromotive force, and from this computed the flux, which was platted against the instantaneous values of current to give an energy loop. In a massive specimen he obtained large changes with the frequency of course, but in the thinnest wire, where eddy currents are excluded, there was no effect up to 60 cycles.

\footnotetext{
${ }^{13}$ T. R. Lyle, Phil. Mag., 9, p. ro2; r905.

${ }^{14}$ C. Maurain, Journ. d. Phys., (3) 7, p. 46r; r898.

${ }^{15}$ W. Kaufmann, Verh. deuts. phys. Ges., 1, p. 42; 1899.

${ }^{16}$ Guye and Herzfeld, C. R., 136, p. 957; I903; Guye and Schidlof, C. R., 139, p. 5I7; I904.
} 
Willians and Kaufmann used a different apparatus for observing the relative instantaneous values of current and magnetization, which were platted similarly. No effect as great as 2 per cent (limit of accuracy) was found. Both of these methods are subject to the same criticism that applies to the energy loops platted in this article, and the former has the additional disadvantage that the values of flux are not directly determined.

Guye's method consisted in measuring the heat developed in the wire specimen by means of the bolometer. For the finest wire used, $0.0038 \mathrm{~cm}$ in diameter, there is no change in the loss per cycle up to 200 cycles; in the larger wires the increasing loss is explained by eddy currents. The method of determining flux is not mentioned. The accuracy is I per cent.

Batelli and Magri ${ }^{17}$ used a Braun tube for getting the energy loop; and using fine wires $(0.005 \mathrm{~cm}$ in diam.) found the area slightly less at 5000 than at 25 cycles. In large specimens the area is increased at high frequencies, owing to eddy currents.

Gumlich and Rose ${ }^{18}$ platted lcops from instantaneous values with alternating current and from ballistic readings with direct current and found agreement at high inductions and only slight differences at low inductions. By wattmeter measurements they found a slight increase of hysteresis with frequency below I 2000 gausses. Their method involved the separation of the eddy current loss by the Steinmetz formula.

Peukert ${ }^{19}$ also claimed to find an increase of hysteresis with frequency, but it is to be noted that he assumes a sine wave and calculates the eddy current loss.

The latest research in this field is by Schames, ${ }^{20}$ who reverts to a calorimetric method, and finds that above Ioooo gausses the hysteresis increases with frequency, but below that flux density is constant. His specimens were straight strips; frequencies of 400 and 500 cycles per second were used. The curve of secondary emf. was platted to obtain the maximum flux density, the secondary coil being placed at a point to measure the average value of $B$ throughout the

${ }^{17}$ A. Batelli and L. Magri, Atti Acc. Lincei, 15, p. 485; 1906.

${ }^{18}$ E. Gumlich and P. Rose, Electrot. Zs., 26, p. 503; 1905.

${ }^{19} \mathrm{WV}$. Peukert, Electrot. Zs., 20, p. 674; I899.

${ }^{20}$ L. Schames, Diss.Würzburg 1906; Ann. d. Phys., 22, p. 448; 1907. 
specimen, rather than the average value of $B^{1.6}$. The flux density varied through wide limits between the middle and end of the strips, and this distribution might vary with the frequency on account of the effect of eddy currents. The eddy current loss was not measured but computed, and although it was considered negligible for the thinner specimens it amounted to half the measured loss in other cases. The author further admits that the value of this correction is very uncertain. The secondary voltage could not be read to better than 2 per cent except for inductions above roooo gausses. In view of these facts we must conclude that the absolute values given by Schames are doubtful, and as to qualitative results they show that the effect of frequency can not be large, but must either be smalı or nil.

\section{CONCLUSIONS.}

For a definite maximum value of the flux density, the hysteresis is greater with a flat wave of flux, but the effect is small, and from the industrial standpoint negligible, even with very distorted waves.

If, however, the wave of flux is dimpled, the hysteresis may be much increased.

The hysteresis determined by the ballistic method may be smaller than that which obtains with the use of alternating current, but the differences are small.

The separation of hysteresis and eddy current losses by means of runs at two frequencies, using the Steinmetz formula, is not accurate, but is a close approximation when the sheets are thin.

WASHington, October Io, I908. 